\title{
Statins and atrial fibrillation - mini-review on recent evidence
}

\author{
Bożena Sosnowska'1,B,D, Maciej Banach ${ }^{1-2, A, E-F}$ \\ A - Research concept and design, B - Collection and/or assembly of data, C - Data analysis and interpretation, \\ D - Writing the article, E - Critical revision of the article, F - Final approval of article \\ 1 Department of Hypertension, Chair of Nephrology and Hypertension, Medical University of Lodz, Lodz, Poland \\ 2 Polish Mother's Memorial Hospital Research Institute (PMMHRI), Lodz, Poland
}

Address for correspondence:

Bożena Sosnowska, Medical University of Lodz, Poland

email: bozena.sosnowska@umed.lodz.pl

Prof. Maciej Banach, MD, PhD, FNLA, FAHA, FESC; FASA, Head, Department of Hypertension, WAM University Hospital in Lodz, Medical University of Lodz, Zeromskiego 113; 90-549 Lodz, Poland. Phone: +48 42639 37 71; Fax: +48 42639 37 71; E-mail: maciejbanach@aol.co.uk

Received: 27.12.2016

Revised: 27.12.2016

Accepted: 27.12.2016

\section{Key words:}

\section{statins, atrial fibrillation, cardiac surgery, prevention}

\section{Abstract}

Atrial fibrillation (AF) is the most common clinically significant cardiac arrhythmia, and it is associated with higher morbidity and mortality. However, treatment options for AF are still limited and often not effective. Studies have indicated

\section{Introduction}

Atrial fibrillation $(\mathrm{AF})$ is a supraventricular tachyarrhythmia characterized by uncoordinated atrial activation with subsequent deterioration of atrial mechanical function (Andrade et al., 2014). AF is the most common clinically significant cardiac arrhythmia, and it is an independent risk factor for cardiovascular (CV) morbidity and mortality (Benjamin et al., 1998). Patients with AF have a five-fold higher risk of stroke and two-fold higher risk of death (Friberg et al., 2010; Chamberlain et al., 2011). Nowadays, AF is one of the most important

\section{Statins in postoperative AF}

$\mathrm{AF}$ is the most common postoperative complication after cardiothoracic and non-cardiothoracic surgery (Banach et al. 2007 \& 2010). Frequency of postoperative atrial fibrillation (POAF) despite implementation of several drug therapies might reach even 65\% (Mathew et al., 2004; Patti et al., 2006). The mechanism for the occurrence of postoperative AF has been postulated to be associated with increased levels of systemic inflammatory markers and oxidative stress parameters preoperatively (Aviles et al., 2003). Several studies have indicated an association between AF and various inflammatory that statins might be associated with a decreased risk of occurrence or recurrence of AF. The following review summarizes the key findings of the recently published studies.

public health issues, which leads to increased health care costs in western countries (Zoni-Berisso et al., 2014).

Based on the available data, risk factors involved in the development of $\mathrm{AF}$ include sex, age, body mass index (BMI), total cholesterol (TC), hypertension and diabetes mellitus (DMt2) (Magnani et al., 2011; January et al., 2014). Moreover, it has been indicated that inflammation might also play a significant role in the development of AF (Guo et al., 2012); therefore it has been suggested that statins might be effective anti-AF drugs.

markers, such as high-sensitivity C-reactive protein (hs-CRP) and TC (Guo et al., 2012; Shi et al., 2015). Other studies have also suggested a role of preoperative arrhythmias as a predictor of POAF (Banach et al. 2007).

Statins are the most effective drugs to treat hypercholesterolemia (Hobbs et al. 2016). Available studies indicated that statin therapy might be effective in protecting against AF in acute coronary syndrome (ACS) (Zhou et al., 2013) and coronary artery disease (CAD) (Zhou et al., 2013a), but the strongest evidence for AF prevention by statin intake is in post-cardiac surgery patients (Kuhn et al., 2014). 
The mechanism whereby statin might prevent AF has not been fully clarified, but it might involve the pleiotropic effects of anti-inflammatory and antioxidant activities, prevention of endothelial dysfunction and neurohormonal activation (Adam et al., 2008).

Most studies showing a decrease in POAF associated with statin use have been conducted in patients undergoing cardiac surgery (Mariscalco et al., 2007; Kourliouros et al., 2008; Patti et al., 2006). A recent meta-analysis based on the results of 15 clinical studies carried out on 9369 patients of whom 5598 (59.75\%) used statins and 3771 (49.25\%) did not receive them also confirmed the beneficial role of statin therapy prior to coronary artery bypass grafting (CABG) (Bokeriya et al., 2016). Statin treatment decreased the frequency of AF soon after coronary bypass surgery (OR 0.481 at $95 \%$ CI $0.345-0.672$; $p$ $<0.001$ ) and decreased the frequency of cerebral circulation disorders (OR 0.067 at 95\% CI 0.037-0.121; p < 0.001) (Bokeriya et al., 2016). Efficacy of preoperative statin therapy in patients who underwent CABG was also confirmed in a retrospective study by Bockeria et al. (2016).

In other types of cardiac surgery, such as isolated cardiac valve surgery, Bolesta and Kong (2015) indicated that pre-operative statin use was not associated with a decreased incidence of POAF. The results of this retrospective study of 244 adults may be associated with the fact that the duration of preoperative statin use and the statin dose were unknown and were not included in the analysis. Moreover, patients after isolated cardiac valve surgery may undergo a different inflammatory and oxidative response than patients after reperfusion surgery (Bolesta and Kong 2015).

A recent meta-analysis (Razaei et al., 2016), which included 12 randomized controlled trials (RCTs) involving 1116 patients, indicated that perioperative statin therapy in statin-naive patients with sinus rhythm undergoing cardiac surgery led to a decrease in the development of POAF, the hospital length of stay (LOS), and the CRP level. Moreover, it was found that the beneficial effects on AF occurrence and CRP level were more marked in patients receiving atorvastatin compared to other statins (Razaei et al., 2016).

In patients undergoing non-transplant cardiac surgery, pre-operative use of statins has proven to be beneficial in many studies. However, data on the influence of pre-operative statin therapy in heart transplant surgery are lacking. A recent retrospective study on the influence of pre-transplant statin treatment on clinical outcomes after heart transplantation indicated that pre-operative statin therapy does not seem to influence the risk of mortality or early POAF after heart transplantation (Krishnan et al., 2016). These are preliminary findings, which should be confirmed by further large-scale prospective clinical studies.

Chronic kidney disease (CKD) can greatly increase the risk of developing AF (Alonso et al., 2011). Previous studies indicated no beneficial effect on reduction of any CV event of statin therapy in dialysis patients (Wanner et al., 2005, Barylski et al. 2013). Studies of Ho et al. (2015) showed that statin therapy was associated with lower risk of newly diagnosed $\mathrm{AF}$ in dialysis patients. The authors of that study observed a significant dose-dependent inverse association between new-onset AF and statin use for total accumulated doses. The protective effect was especially seen among patients who received the highest total statin dosage.

\section{Type and dose of statin in atrial fibrillation}

The exact difference of different types of statin in preventing POAF occurrence has not been sufficiently investigated. Atorvastatin is a highly effective statin and is the most studied statin in relation to AF (Fauchier et al., 2013; Yang et al., 2014). The influence of preoperative treatment of atorvastatin before cardiac surgery on POAF reduction is, however, conflicting. There are studies which confirm the benefit of atorvastatin in AF reduction (Patti et al., 2006), but there are also studies with the opposite results (Tamura et al., 2010). Recently Elgendy et al. (2015) elucidated in a metaanalysis of 12 RCTs postoperative reduction in $\mathrm{AF}$ occurrence with atorvastatin (lipophilic statin) 20 to $40 \mathrm{mg}$ but not with rosuvastatin (hydrophilic statin) in patients who underwent isolated CABG. The result from this study suggested that earlier initiation of statin therapy before CABG might increase the reduction of the postoperative AF risk.

Advanced age is indicated as a major risk factor for the development POAF after cardiac surgery (Mathew at al., 1996). Data on whether pre-operative statin therapy is beneficial in advanced age patients on POAF occurrence is lacking. Recently, Kunt et al. (2015) demonstrated no influence of pre-treatment with atorvastatin in doses of 20 and $40 \mathrm{mg}$ on AF reduction after cardiac surgery in patients aged over seventy years. The authors also found no association between dose and duration of statin therapy for the development of POAF (Kunt et al., 2015).

Results concerning the influence of the dose of atorvastatin on POAF occurrence are also conflicting. Some studies indicate that higher dose statins have a greater preventive effect, in comparison to low-dose statins (Lertsburapa et al., 2008), while others report opposite findings (Wang et al., 2011). There are also studies which found equal benefits of high and low dosage of statins in prevention of AF (Karimi et al., 2012).

Pierri et al. (2016) studied the influence of seven-day preoperative treatment with two different dosages of atorvastatin on the incidence of POAF in 212 patients undergoing elective first-time on-pump CABG. The authors reported that comparing treatment with $80 \mathrm{mg}$ and $40 \mathrm{mg}$ of atorvastatin, the higher dosage group had lower incidence of POAF but the difference was not significant. Moreover, there was no significant difference between the treatment of these two dosages of statin and the level of hsCRP and interleukin-6 (IL-6) at 12 and $24 \mathrm{~h}$. The recent study of Zheng et al. (2016) indicated that perioperative rosuvastatin therapy at a dose of $20 \mathrm{mg}$ daily did not prevent POAF in patients undergoing elective CABG and was associated with an increased risk of postoperative acute kidney injury (Zheng et al., 2016). The results of this trial are inconsistent with the previous studies. It could be explained by short duration of preoperative treatment, which 
might have decreased the pleiotropic effects of statin therapy (Barakat et al., 2016).

One of the factors which could influence the beneficial effect of preoperative statin therapy on POAF is the duration of statin therapy. Some studies have suggested that statins reveal their full pleiotropic effect in 14 days of treatment (Barakat et al., 2016a). Meta-regression analysis indicated that preoperative statin use was associated with a 3\% reduction in the risk of POAF per day of therapy (Chen et al., 2010).

\section{Conclusions}

Until now, the strongest evidence for AF prevention by statin therapy is in post-cardiac surgery patients. Recently published studies on the use of statins against AF have focused mainly on the prevention of AF after cardiac surgery. Most studies have confirmed the decrease in occurrence of post-operative AF with pre-operative therapy. Despite the increasing number of studies on this issue, the mechanism of pre-operative statin treatment on POAF incidence reduction is still not fully elucidated. The hypothetical mechanism of action of statins might be associated with their anti-inflammatory and antioxidant properties (Adam et al., 2008).

The effect of statin on postoperative AF might depend on many factors including type of statin and dosage. The difference in impact of different types and doses of statins on AF is not fully clear. Statin therapy is recommended to be started approximately 14 days before surgery (Elgendy et al., 2015).

\section{References}

1. Adam $\mathrm{O}$, Neuberger HR, Böhm M, et al. Prevention of atrial fibrillation with 3-hydroxy-3-methylglutaryl coenzyme A reductase inhibitors. Circulation. 2008; 118:1285-1293.

2. Alonso A, Lopez FL, Matsushita K, Loehr LR, Agarwal SK, Chen LY, Soliman EZ, Astor BC, Coresh J. Chronic kidney disease is associated with the incidence of atrial fibrillation: the Atherosclerosis Risk in Communities (ARIC) study. Circulation. 2011 Jun 28;123(25):2946-53.

3. Andrade J, Khairy P, Dobrev D, Nattel S. The clinical profile and pathophysiology of atrial fibrillation: relationships among clinical features, epidemiology, and mechanisms. Circ Res 2014, 114, 1453-1468.

4. Aviles RJ, Martin DO, Apperson-Hansen C, Houghtaling PL, Rautaharju P, Kronmal RA, Tracy RP, Van Wagoner DR, Psaty BM, Lauer MS, Chung MK. Inflammation as a risk factor for atrial fibrillation. Circulation. 2003 Dec 16;108(24):3006-10.

5. Banach M, Misztal M, Goch A, Rysz J, Goch JH. Predictors of atrial fibrillation in patients following isolated surgical revascularization. A metaanalysis of 9 studies with 28786 patients. Arch Med Sci 2007;3(3):229-239.

6. Banach M, Kourliouros A, Reinhart KM, Benussi S, Mikhailidis DP, Jahangiri M, Baker WL, Galanti A, Rysz J, Camm JA, White CM, Alfieri O. Postoperative atrial fibrillation - what do we really know? Curr Vasc Pharmacol. 2010 Jul;8(4):553-72.
7. Barakat AF, Mahmoud AN, Elgendy IY. Atrial fibrillation post coronary artery bypass surgery: is there still a role for perioperative statins after STICS? J Thorac Dis. 2016 Aug;8(8):1880-2.

8. Barakat AF, Saad M, Abuzaid A, Mentias A, Mahmoud A, Elgendy IY. Perioperative statin therapy for patients undergoing coronary artery bypass grafting. Ann Thorac Surg 2016a; 101: 818-25.

9. Barylski M, Nikfar S, Mikhailidis DP, Toth PP, Salari P, Ray KK, Pencina MJ, Rizzo M, Rysz J, Abdollahi M, Nicholls SJ, Banach M; Lipid and Blood Pressure Meta-Analysis Collaboration Group. Statins decrease all-cause mortality only in CKD patients not requiring dialysis therapy - a meta-analysis of 11 randomized controlled trials involving 21,295 participants. Pharmacol Res. 2013 Jun;72:35-44.

10. Benjamin EJ, Wolf PA, D'Agostino RB, Silbershatz $\mathrm{H}$, Kannel WB, Levy D. Impact of atrial fibrillation on the risk of death: the Framingham Heart Study. Circulation. 1998 Sep 8;98(10):946-52.

11. Bockeria OL, Shvartza VA, Akhobekova AA, Kiseleva AR, Prokhorovb MD, Golukhovac EZ, Bockeriadl LA. Statin therapy in the primary prevention of early atrial fibrillation after coronary artery bypass grafting, Indian Heart J. 2016, http://dx.doi.org/10.1016/j.ihj.2016.04.002.

12. Bokeriya OL, Akhobekov AA, Shvarts VA, Glushko LA, Le TG. Meta-analysis of clinical studies on the use of statins for prevention of atrial fibrillation soon after coronary bypass surgery. Klin Med (Mosk). 2016;94(2):85-92.

13. Bolesta S, Kong F. Effect of statins on the incidence of postoperative atrial fibrillation after cardiac valve surgery. Pharmacotherapy. 2015 Nov;35(11):998-1006.

14. Chamberlain AM, Redfield MM, Alonso A, Weston SA, Roger VL. Atrial fibrillation and mortality in heart failure: a community study. Circ Heart Fail. 2011;4:740-746.

15. Chen WT, Krishnan GM, Sood N, Kluger J, Coleman CI. Effect of statins on atrial fibrillation after cardiac surgery: a duration and dose-response meta-analysis. J Thorac Cardiovasc Surg 2010; 140: 364-72.

16. Elgendy IY, Mahmoud A, Huo T, Beaver TM, Bavry AA. Meta-analysis of 12 trials evaluating the effects of statins on decreasing atrial fibrillation after coronary artery bypass grafting. Am J Cardiol 2015;115:1523e1528.

17. Fauchier L, Clementy N, Babuty D. Statin therapy and atrial fibrillation: systematic review and updated meta-analysis of published randomized controlled trials. Curr Opin Cardiol. 2013, 28: 7-18.

18. Friberg L, Hammar N, Rosenqvist M. Stroke in paroxysmal atrial fibrillation: report from the Stockholm Cohort of Atrial Fibrillation. Eur Heart J. 2010;31:967-972.

19. Guo Y, Lip GY, Apostolakis S. Inflammation in atrial fibrillation. J Am. Coll. Cardiol. 2012; 60: 2263-2270.

20. Ho LT, Lin LY, Yang YH, Wu CK, Juang JM, Wang YC, Tsai CT, Lai LP, Hwang JJ, Chiang FT, Lin JL, Chen PC. Statin therapy lowers the risk of new-onset atrial 
fibrillation in patients with end-stage renal disease. Int J Cardiol. 2015 Dec 15;201:538-43.

21. Hobbs FD, Banach M, Mikhailidis DP, Malhotra A, Capewell S. Is statin-modified reduction in lipids the most important preventive therapy for cardiovascular disease? A pro/con debate. BMC Med. 2016 Jan 14;14:4.

22. January CT, Wann LS, Alpert JS, Calkins H, Cleveland JC Jr, Cigarroa JE, et al. AHA/ACC/HRS guideline for the management of patients with atrial fibrillation: a report of the American College of Cardiology/ American Heart Association Task Force on Practice Guidelines and the Heart Rhythm Society. J. Am. Coll. Cardiol. 2014.

23. Karimi A, Bidhendi LM, Rezvanfard M, Bina P, Yousefi A, Molai M, et al. The effect of a high dose of atorvastatin on the occurrence of atrial fibrillation after coronary artery bypass grafting. Ann Thorac Surg. 2012;94(1):8-14.

24. Kourliouros A, De SA, Roberts N, et al. Dose-related effect of statins on atrial fibrillation after cardiac surgery. Ann Thorac Surg 2008;85(5):1515-20.

25. Krishnan B, Vakil KP, Sankar A, Duprez D, Benditt DG. Impact of pre-operative statin use on risk of mortality and early atrial fibrillation after heart transplantation. Clin Transplant. 2016 May;30(5):628-32.

26. Kuhn EW, Liakopoulos OJ, Stange S, Deppe AC, Slottosch I, Choi YH, et al. Preoperative statin therapy in cardiac surgery: a meta-analysis of 90,000 patients, Eur. J. Cardiothorac. Surg. 45 (2014) 17-26.

27. Kunt A, Özcan S, Küçüker A, Odabaşi D, Sami Kunt A. Effects of perioperative statin treatment on postoperative atrial fibrillation and cardiac mortality in patients undergoing coronary artery bypass grafting: a propensity score analysis. Med Glas (Zenica). 2015 Aug;12(2):190-5.

28. Lertsburapa K, White CM, Kluger J, Faheem O, Hammond J, Coleman CI. Preoperative statins for the prevention of atrial fibrillation after cardiothoracic surgery. J Thorac Cardiovasc Surg. 2008;135(2):405-11.

29. Magnani JW, Rienstra M, Lin H, Sinner MF, Lubitz SA, McManus DD, Dupuis J, Ellinor PT, Benjamin EJ. Atrial fibrillation: Current knowledge and future directions in epidemiology and genomics. Circulation. 2011;124:1982-1993.

30. Mariscalco G, Lorusso R, Klersy C, et al. Observational study on the beneficial effect of preoperative statins in reducing atrial fibrillation after coronary surgery. Ann Thorac Surg 2007;84(4):1158-64.

31. Mathew JP, Fontes ML, Tudor IC, et al. A multicenter risk index for atrial fibrillation after cardiac surgery. JAMA. 2004;291:1720-1729.

32. Mathew JP, Parks R, Savino JS, Friedman AS, Koch C, Mangano DT. Atrial fibrillation following coronary artery bypass graft surgery. JAMA 1996; 276:300- 6 .

33. Patti G, Chello M, Candura D, Pasceri V, D'Ambrosio A, Covino E, Di Sciascio G. Randomized trial of atorvastatin for reduction of postoperative atrial fibrillation in patients undergoing cardiac surgery: results of the ARMYDA-3 (Atorvastatin for Reduction of MYocardial Dysrhythmia After cardiac surgery) study. Circulation 2006;114:1455-1461.

34. Pierri MD, Crescenzi G, Zingaro C, D'Alfonso A, Capestro F, Scocco V, Brugia M, Torracca L. Prevention of atrial fibrillation and inflammatory response after on-pump coronary artery bypass using different statin dosages: a randomized, controlled trial. Gen Thorac Cardiovasc Surg 2016; 64:395-402.

35. Rezaei $Y$, Gholami-Fesharaki M, Dehghani MR, Arya A, Haghjoo M, Arjmand N. Statin antiarrhythmic effect on atrial fibrillation in statin-naive patients undergoing cardiac surgery: a meta-analysis of randomized controlled trials. J Cardiovasc Pharmacol Ther. 2016 Mar;21(2):167-76.

36. Shi MY, Xue FH, Teng SC, Jiang L, Zhu J, Yin F, Gu HY. Effect of atorvastatin on serum levels of total cholesterol and high-sensitivity C-reactive protein in high-risk patients with atrial fibrillation in Asia. Clin Ther. 2015 Aug;37(8):1740-50.

37. Tamura K, Arai H, Ito F, Someya T, Ushiyama T, Miyagi N. Pravastatin treatment before coronary artery bypass grafting for reduction of postoperative atrial fibrillation. Gen Thorac Cardiovasc Surg 2010;58(3):120-5.

38. Wang Z, Zhang Y, Gao M, Wang J, Wang Q, Wang X, Su L, Hou Y. Statin therapy for the prevention of atrial fibrillation: a meta-analysis of randomized controlled trials. Pharmacotherapy 2011; 31,1051-1062.

39. Wanner C, Krane V, März W, Olschewski M, Mann JF, Ruf G, Ritz E, German Diabetes and Dialysis Study Investigators. Atorvastatin in patients with type 2 diabetes mellitus undergoing hemodialysis. N Engl J Med. 2005 Jul 21;353(3):238-48.

40. Yang $Q, Q i X, L i Y$. The preventive effect of atorvastatin on atrial fibrillation: a meta-analysis of randomized controlled trials. BMC Cardiovasc Disord. 2014 Aug 13;14:99.

41. Zheng Z, Jayaram R, Jiang L, Emberson J, Zhao Y, Li Q, Du J, Guarguagli S, Hill M, Chen Z, Collins R, Casadei B. Perioperative rosuvastatin in cardiac surgery. $N$ Engl J Med. 2016; 5;374(18):1744-53.

42. Zhou X, Du JL, Yuan J, Chen YQ. Statin therapy is beneficial for the prevention of atrial fibrillation in patients with coronary artery disease: a meta-analysis. Eur J Pharmacol. 2013a; 5,707(1-3):104-11.

43. Zhou X, Du JL, Yuan J, Chen YQ. Statins therapy can reduce the risk of atrial fibrillation in patients with acute coronary syndrome: a meta-analysis. Int J Med Sci. 2013;10(2):198-205.

44. Zoni-Berisso M, Lercari F, Carazza T, Domenicucci S. Epidemiology of atrial fibrillation: European perspective. Clin Epidemiol. 2014; 16;6:213-20. 